\title{
Future Enhancement of Heavy Rainfall Events Associated with a Typhoon in the Midlatitude Regions
}

\author{
Sachie Kanada ${ }^{1}$, Kazuhisa Tsuboki ${ }^{1}$, Hidenori Aiki ${ }^{1,2}$, Satoki Tsujino ${ }^{1}$, and Izuru Takayabu ${ }^{3}$ \\ ${ }^{1}$ Institute for Space-Earth Environmental Research, Nagoya University, Nagoya, Japan \\ ${ }^{2} J a p a n$ Agency for Marine-Earth Science and Technology, Yokohama, Japan \\ ${ }^{3}$ Meteorological Research Institute, Tsukuba, Japan
}

\begin{abstract}
In August 2016, eastern Hokkaido in northern Japan had unusual typhoon landfalls and experienced heavy rainfall events that caused severe disasters. To understand the impact of global warming on typhoon-related rainfall in such midlatitude regions, numerical experiments on one of the typhoons in August 2016, Typhoon Chanthu, were conducted by using a high-resolution three-dimensional atmosphere-ocean coupled regional model in current and pseudo-global warming (PGW) climates. The amount, intensity, and duration of rainfall in eastern Hokkaido associated with the typhoon increased in the warming climate. The PGW typhoon traveled northward with relatively slower translation speed and resulted in a delay in the landfalls for $6 \mathrm{~h}$. Furthermore, large amounts of near-surface water vapor $>22 \mathrm{~g} \mathrm{~kg}^{-1}$ from the southern sea increased the convective instability around eastern Hokkaido and caused tall and intense updrafts. As a result, significant predecessor rainfall events with intense rainfall developed about $24 \mathrm{~h}$ before the typhoon landfall. Increased near-surface water vapor in the warming climate also enhanced rainfall associated with the typhoon passage over a widespread area. These results suggest that attention should be paid to future enhancement of heavy rainfall events in the midlatitude regions under global warming.

(Citation: Kanada, S., K. Tsuboki, H. Aiki, S. Tsujino, and I. Takayabu, 2017: Future enhancement of heavy rainfall events associated with a typhoon in the midlatitude regions. SOLA, 13, 246-251, doi:10.2151/sola.2017-045.)
\end{abstract}

\section{Introduction}

Recent studies have reported that observed extreme rainfall increases as the surface air temperature increases (e.g., Trenberth 2011). Fujibe (2015) investigated long-term changes in extreme hourly rainfall in Japan and demonstrated that the increase in extreme rainfall from 1979 to 2013 was a nationwide feature as the air temperature rose. These results indicate that the risk of severe disasters increases in a warming climate.

A number of climate runs that use state-of-the-art general circulation models have projected increases in sea surface temperature (SST) in the future climate (Collins et al. 2013). Atmospheric water vapor increases as surface air temperature increases (Fujita and Sato 2017), and with increased moisture, storms can produce larger amounts of and more intense rainfall. On the other hand, most studies have pointed out that the increase in air temperature is large in the upper troposphere, which suggests stabilization of atmospheric conditions in the future climate (e.g., Hill and Lackmann 2011; Kanada et al. 2017). This raises questions regarding whether and how storms and the resulting rainfall will change in the vicinity of Japan.

In August 2016, eastern Hokkaido in northern Japan (Fig. 1a) experienced heavy rainfall that caused severe disasters associated with three typhoon landfalls. According to the Regional Specialized Meteorological Center (RSMC) Tokyo Best Track dataset,

Corresponding author: Sachie Kanada, Nagoya University, Furo-cho, Chikusa-ku, Nagoya 464-8601, Japan. E-mail: skanada@nagoya-u.jp. (C)2017, the Meteorological Society of Japan. typhoon landfalls over eastern Hokkaido from the Pacific are very unusual. The $48 \mathrm{~h}$ rainfall amount associated with Typhoon Chanthu (2016), one of the three typhoons that made landfall on eastern Hokkaido, reached $197 \mathrm{~mm}$ in eastern Hokkaido ("A" in Fig. 2a, Nukabira-Gensenkyo station); this amount is nearly the same as the mean monthly rainfall amount of August at the station, 198 $\mathrm{mm}$.

In the present climate, typhoons in August tend to weaken in the north of $35^{\circ} \mathrm{N}$ including Hokkaido comparing with that in low-latitude because SST is relatively low for tropical cyclones (TCs). Meanwhile, the projected future increase in SST is large in the vicinity of Japan; the projected increase around Hokkaido exceeds $4^{\circ} \mathrm{C}$ in the late $21^{\text {st }}$ century (Mizuta et al. 2017). A typhoon transports a large amount of water vapor from the southern sea (e.g., Galarneau et al. 2010). The high SST will be a favorable condition for a TC to maintain its intensity (e.g., Emanuel 1986). Thus, it is important to elucidate changes in heavy rainfall associated with the passage of a typhoon in such midlatitude regions in the future warmer climate.

The present study aims to understand the impact of global warming on typhoon-related rainfall in midlatitude regions such as Hokkaido. For that purpose, numerical experiments on one of the three typhoons in August 2016, Typhoon Chanthu, were conducted by using a high-resolution three-dimensional atmosphereocean coupled regional model in current and pseudo-global warming (PGW) climates. Here, we focus on rainfall events in eastern Hokkaido and explore how the convective activity in eastern Hokkaido responds to given future environmental conditions.

\section{Models and methodology}

The model used in the present study is a high-resolution threedimensional atmosphere-ocean coupled regional model composed of the Cloud Resolving Storm Simulator version 3.4.1 (CReSS; Tsuboki and Sakakibara 2002) for the atmospheric part and the Non-Hydrostatic Ocean model for the Earth Simulator (NHOES; Aiki et al. 2006, 2011) for the oceanic part. The coupled model is referred to as CReSS-NHOES (Aiki et al. 2015). The horizontal domain of the coupled model spans $132^{\circ} \mathrm{E}-155^{\circ} \mathrm{E}$ and $25^{\circ} \mathrm{N}-50^{\circ} \mathrm{N}$ (Fig. 1), and is discretized with a grid spacing of $0.04^{\circ}$ by $0.04^{\circ}$.

The PGW simulations were conducted by the same procedure as in Kanada et al. (2017). First, a control simulation of Typhoon Chanthu in the current climate (the CNTL simulation) was performed. Initial and lateral boundary conditions for the atmosphere model were provided every $6 \mathrm{~h}$ from the Japan Meteorological Agency 55-year Reanalysis (JRA55, Kobayashi et al. 2015). For the ocean model, the boundary conditions were provided every 24 $\mathrm{h}$ from the Japan Coastal Ocean Predictability Experiment reanalysis product (Miyazawa et al. 2009).

To make the PGW increments, the results of climate runs by MRI-AGCM version 3.2 with a horizontal resolution of $20 \mathrm{~km}$ (Mizuta et al. 2012) were used. The future climate runs were driven by a multi-model ensemble mean SST pattern projected by Coupled Model Intercomparison Project phase 5 models under the RCP8.5 scenario (Mizuta et al. 2014). Then, changes between the periods of 1979-2003 and 2075-2099 were estimated from the results, and these changes were added to the initial and boundary conditions of the CNTL simulation. Future changes in the August 

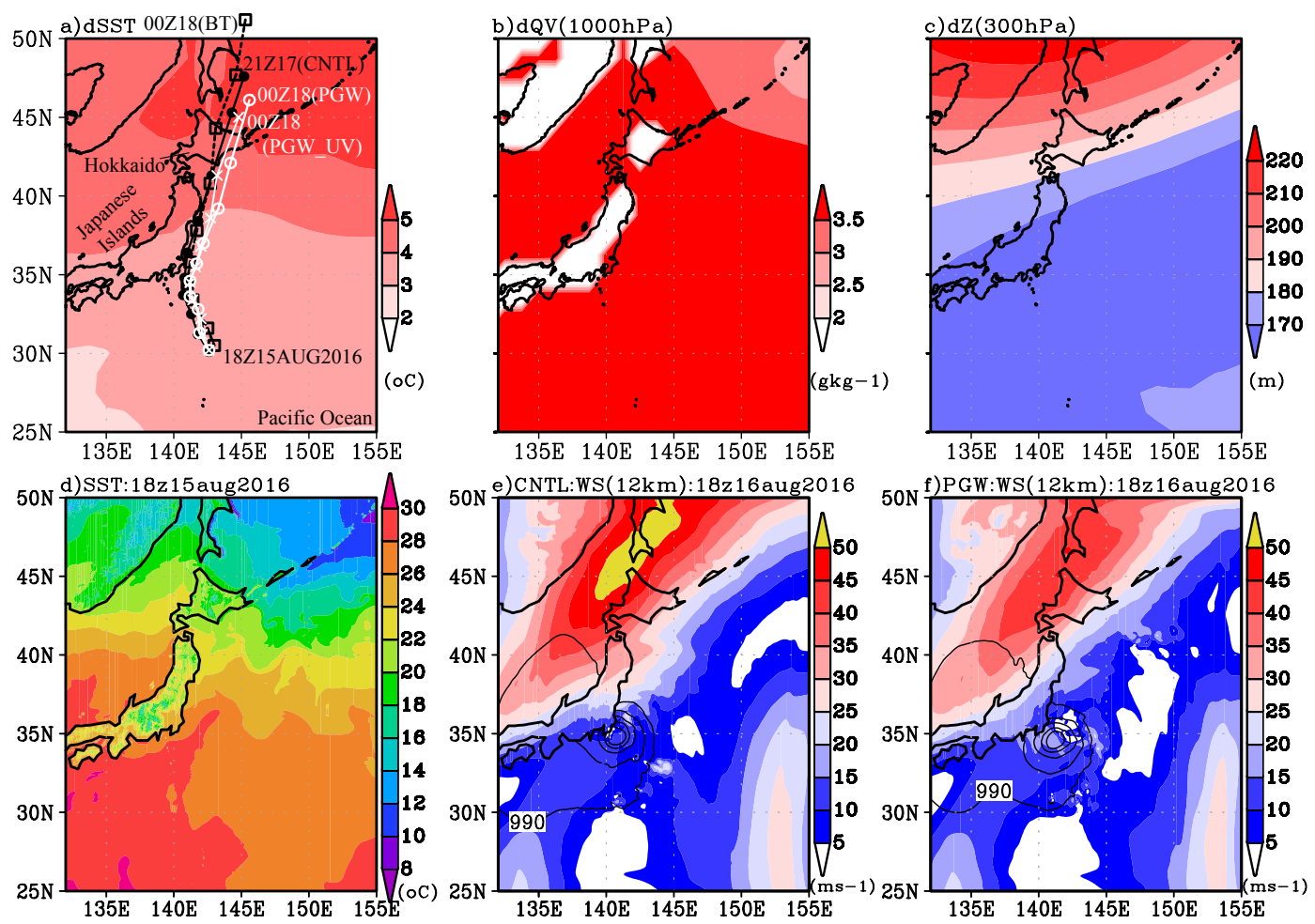

Fig. 1. Horizontal distributions of the pseudo-global warming (PGW) increments for (a) sea surface temperature (dSST: $\left.{ }^{\circ} \mathrm{C}\right)$, (b) water vapor mixing ratio at an altitude of $1000 \mathrm{hPa}\left(\mathrm{dQV}: \mathrm{g} \mathrm{kg}^{-1}\right.$ ), and (c) geopotential height at an altitude of $300 \mathrm{hPa}(\mathrm{dT}: \mathrm{m})$. Six-hourly tracks of the RSMC besttrack (black dotted-line with open square marks), CNTL (black line with dots), PGW (white line with open circles), and PGW UV (white line with crosses) simulations are shown in (a). Horizontal distributions of (d) sea surface temperature (SST: ${ }^{\circ} \mathrm{C}$ ) at $1800 \mathrm{UTC} 15$ August 2016, and wind speed at an altitude of $12 \mathrm{~km}$ (WS: $\mathrm{m} \mathrm{s}^{-1}$ ) at 1800 UTC 16 August 2016 for the (e) CNTL and (f) PGW simulations. Contours in (e) and (f) indicate sea level pressures of 978, 981, 984, 987, and $990 \mathrm{hPa}$.
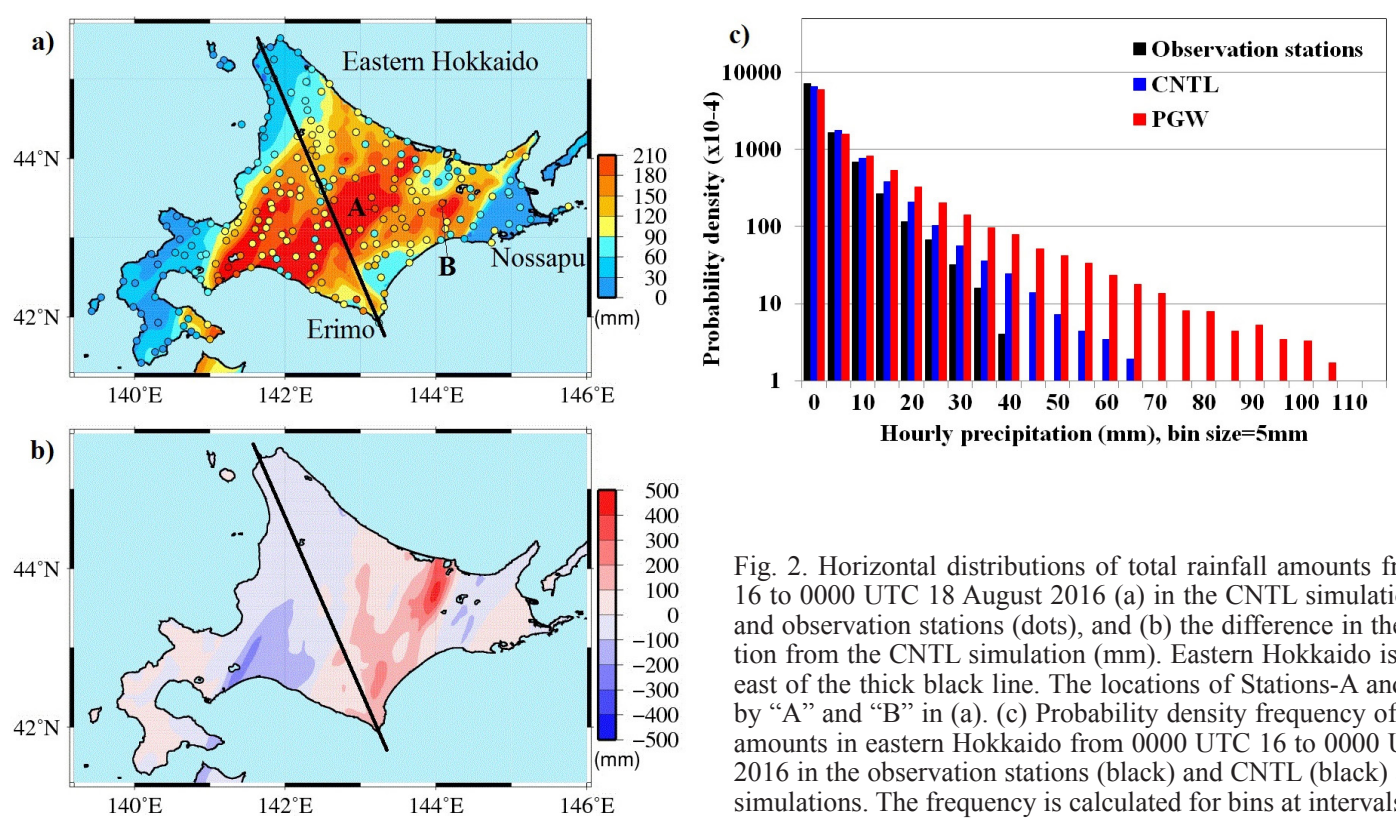

Fig. 2. Horizontal distributions of total rainfall amounts from 0000 UTC 16 to 0000 UTC 18 August 2016 (a) in the CNTL simulation (mm: color) and observation stations (dots), and (b) the difference in the PWG simulation from the CNTL simulation (mm). Eastern Hokkaido is the area to the east of the thick black line. The locations of Stations-A and -B are shown by " $A$ " and "B" in (a). (c) Probability density frequency of hourly rainfall amounts in eastern Hokkaido from 0000 UTC 16 to 0000 UTC 18 August 2016 in the observation stations (black) and CNTL (black) and PGW (red) simulations. The frequency is calculated for bins at intervals of $5 \mathrm{~mm} \mathrm{~h}^{-1}$.

monthly mean for SST, atmospheric temperature (T), and water vapor $(\mathrm{QV})$ were added to the initial and boundary conditions of the CNTL simulation for the PGW simulation. We also conducted the PGW simulation with wind increments (hereafter, the PGW UV simulation) to study the impacts of changes in vertical wind shear. Table 1 summarizes the simulations. More detailed information for the models and methodology are found in Supplement 1.

\section{Results}

The CNTL simulation successfully represented the track and minimum central pressure (MCP) of Typhoon Chanthu compared with the RSMC best-track dataset, although the appearance time of MCP was delayed for $6 \mathrm{~h}$ (Table 1 and Fig. 1a). The maximum intensity increased slightly in the PGW simulations. Both the 
Table 1. List of simulations with the given pseudo-global warming (PGW) increments and minimum central pressure.

\begin{tabular}{ccc}
\hline Experiments & PGW increments & $\begin{array}{c}\text { Minimum central } \\
\text { pressure }\end{array}$ \\
\hline RSMC besttrack & N/A & 980 \\
CNTL & N/A & 977 \\
PWG & T, Z, QV, SST + T & 973 \\
PWG_UV & T, Z, QV, SST, Wind + T & ocean \\
\hline
\end{tabular}

PGW and PGW UV typhoons traveled northward with relatively slow translation speeds, and the tracks tended to shift eastward from that in the CNTL simulation (Fig. 1a). The slow translation speeds resulted in delays in the landfalls for the PGW $(6 \mathrm{~h})$ and PGW_UV (7 h) typhoons compared to the CNTL typhoon. Under the warming climate, increases in SST and air temperature in the vicinity of Japan were larger in the higher latitudes than those in the lower latitudes (Figs. 1a and 1c), which led to a weakening of the jet streak along Japan (Figs. 1e and 1f) due to the reduction of baroclinicity (Ito et al. 2016). The weakening of the jet streak was a possible factor for the slower translation speeds. The water vapor mixing ratio in the lower troposphere increased by $3.5 \mathrm{~g} \mathrm{~kg}^{-1}$ in response to the SST increase of 3-5 K (Figs. 1a and $1 \mathrm{~b}$ ).

Figure 2a presents the horizontal distributions of total rainfall amounts from 0000 UTC 16 to 0000 UTC 18 August 2016 in the CNTL simulation. During this period, large amounts of rainfall were observed in the eastern side of Hokkaido (Fig. 2a). The pres- ent study focused on future changes in these heavy rainfall events in eastern Hokkaido, which we define as the land east of a straight line between Wakkanai $\left(141.678^{\circ} \mathrm{E}, 45.415^{\circ} \mathrm{N}\right)$ and Cape Erimo $\left(143.243^{\circ} \mathrm{E}, 41.925^{\circ} \mathrm{N}\right)$. The region contains 110 observation stations and 3070 grid points in the simulations. There are two peaks in $48 \mathrm{~h}$ rainfall amounts at Station-A (Nukabira-Gensenkyo, $143.192^{\circ} \mathrm{E}, 43.367^{\circ} \mathrm{N}$ ) and Station-B (Akankohan, $144.08^{\circ} \mathrm{E}$, $43.437^{\circ} \mathrm{N}$ ). The amounts, 197 and $184 \mathrm{~mm}$ at Stations-A and -B, respectively, are nearly the same as the mean monthly rainfall amounts between 1981 and 2010 of August for each station, 198 and $152 \mathrm{~mm}$, respectively. The CNTL simulation represented those peaks and the horizontal pattern of the heavy rainfall events in eastern Hokkaido, although the amounts tended to be overestimated in the western parts and along the northeastern coast of Hokkaido.

The rainfall in eastern Hokkaido associated with Typhoon Chanthu in the warming climate is projected to increase in both amount and intensity. Large increases in the $48 \mathrm{~h}$ rainfall amount between 100 and $300 \mathrm{~mm}$ appear at latitudes between $42^{\circ} \mathrm{N}$ and $44^{\circ} \mathrm{N}$ (Fig. 2b). The appearance frequency of hourly rainfall in the region during the period reveals that the frequency of intense rainfalls will increase and that of weak rainfall will decrease in the warming climate, although the model tended to overestimate the frequency of intense rainfalls (Fig. 2c). The same features are also found in the PGW_UV simulation (not shown).

Temporal evolution of the rainfall in eastern Hokkaido shows that the CNTL simulation successfully reproduced the amount, timing, and duration of mean hourly rainfall (Fig. 3a). At 1400 UTC 17 August 2016, the CNTL typhoon hit eastern
T1607: Eastern Hokkaido

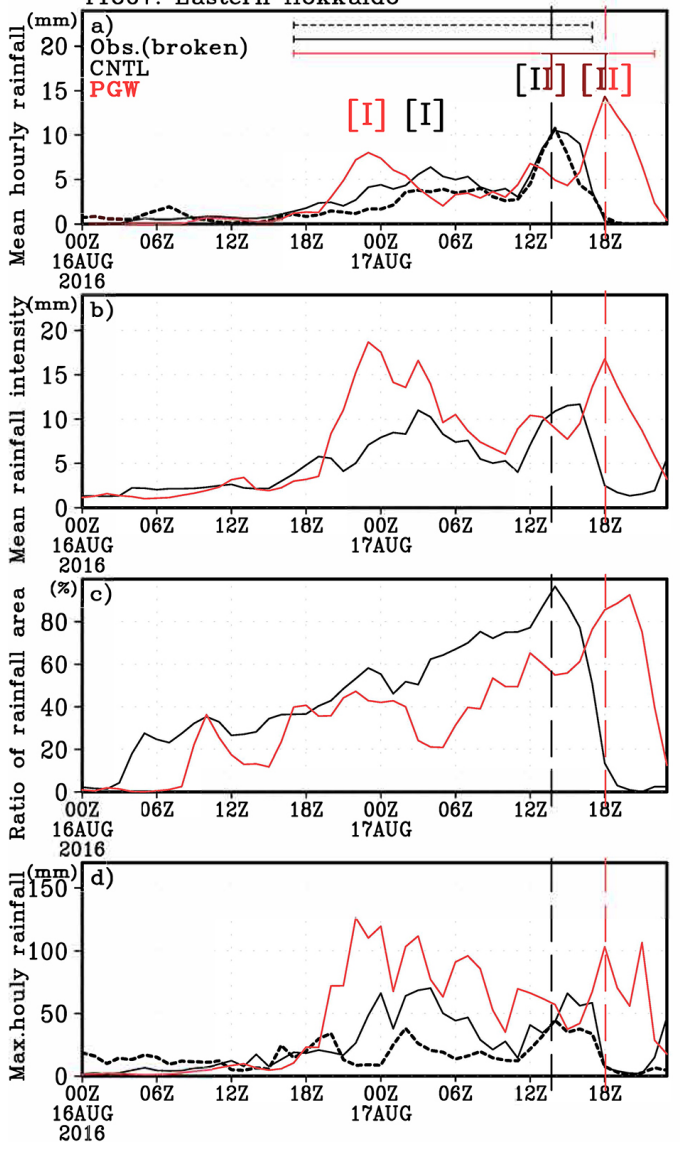

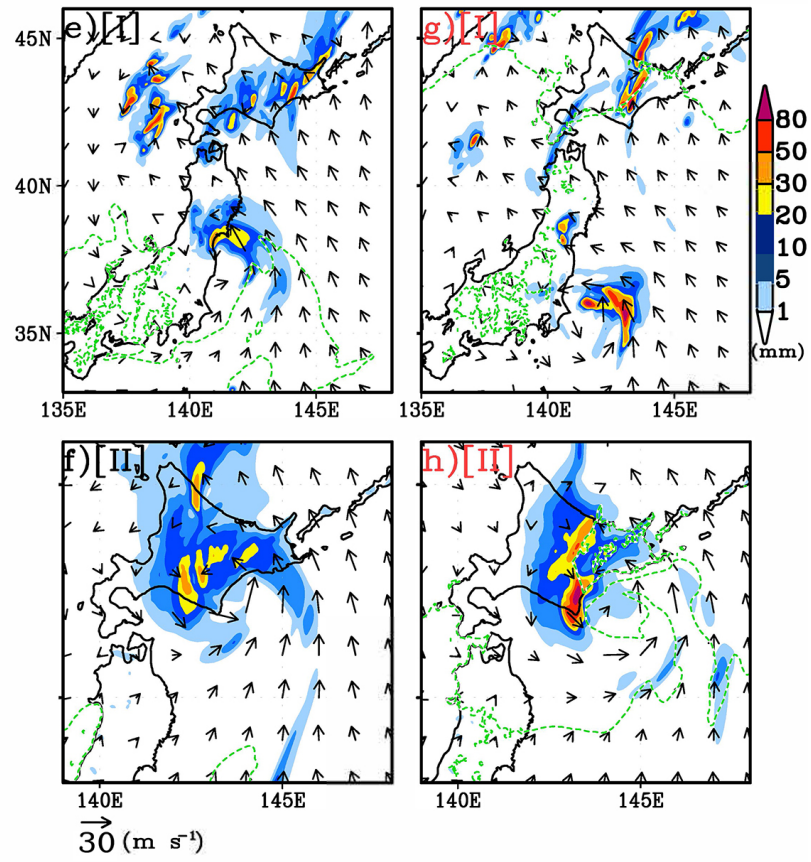

Fig. 3. Temporal evolutions of (a) mean hourly rainfall, (b) mean rainfall intensity, (c) ratio of area with hourly rainfall amount larger than 0.5 mm to the total area of eastern Hokkaido, and (d) the maximum hourly rainfall in eastern Hokkaido in the CNTL (black) and PGW (red) simulations. The thick black dotted lines in (a) and (d) are results from the observation stations. The vertical dashed lines indicate landfall times. The horizontal lines in (a) indicate the periods when the domain-averaged rainfall exceeded $1.0 \mathrm{~mm}$. Horizontal distributions of hourly rainfall for Event-I ([I]) in the (e) CNTL (0400 UTC 17) and (g) PGW (2300 UTC 16) simulations. Black arrows and green broken lines indicate 10-m winds and water vapor amount of $20 \mathrm{~g}$ kg ${ }^{-1}$. (f)-(h) Same as (e)-(g) but for Event-II ([II]) in the (e) CNTL (1400 UTC 17) and (g) PGW (1800 UTC 17) simulations. 
Hokkaido at $42.5^{\circ} \mathrm{N}$ and $143.3^{\circ} \mathrm{E}$. Meanwhile, the PGW typhoon arrived at around $42.5^{\circ} \mathrm{N}$ at 1800 UTC 17 August 2016. The rainfall periods, defined by the period with domain averaged rainfall equal to or larger than $1 \mathrm{~mm} \mathrm{~h}^{-1}$, were $24 \mathrm{~h}$ in the observation and CNTL simulation, while in the PGW simulation the period lasted $29 \mathrm{~h}$ (Fig. 3a). The accumulated domain averaged rainfalls during the rainfall period were 105,129 , and $164 \mathrm{~mm}$ in the observation, CNTL, and PGW simulations, respectively. Figure 3 also reveals that a notable rainfall peak occurred about $24 \mathrm{~h}$ before the landfall in the PGW simulation (Event-I). During Event-I, rainbands formed along the southeastern side of an upper-tropospheric jet streak (Figs. 1f and 3g), where air masses with abundant water vapor above $20 \mathrm{~g} \mathrm{~kg}^{-1}$ were supplied by southeasterly winds. The rainbands in the PGW simulation caused intense rainfall in limited areas (Figs. 3b, 3c and 3d). Similar predecessor rainfall events (PRE) have been reported with North Atlantic TCs (Galarneau et al. 2010; Bosart et al. 2012) as one type of extreme rainproducing mesoscale convective system. The PREs typically occur $\sim 1000 \mathrm{~km}$ poleward of TCs. According to Galarneau et al. (2010), one of the key factors for a PRE is abundant transportation of tropical moisture (precipitable water, $\mathrm{PW}>50 \mathrm{~mm}$ ) from the TC. In the warming climate, extremely moist air masses with PW larger than $70 \mathrm{~mm}$ were also transported to eastern Hokkaido in association with the typhoon southeasterly winds (not shown). On the other hand, water vapor north of $40^{\circ} \mathrm{N}$ never attained $20 \mathrm{~g} \mathrm{~kg}^{-1}$ and there was no significant PREs with intense rainfall in the CNTL simulation (Figs. $3 \mathrm{a}$ and 3e). Abundant water vapor above $20 \mathrm{~g} \mathrm{~kg}^{-1}$ continued to be supplied to eastern Hokkaido in the warmer climate until the typhoon passed over the region. With the passage of the typhoon core region, nearly the entire area of eastern Hokkaido was covered by hourly rainfall of $10 \mathrm{~mm}$ in both the CNTL and PGW simulations (Event-II, Figs. $3 \mathrm{f}$ and $3 \mathrm{~h}$ ).

To understand the mechanism responsible for the PREs with intense rainfall in the warming climate, near-surface water vapor flux, convective instability, and convective activity around eastern Hokkaido were investigated (Figs. 4 and 5). Longitude-time cross sections of near-surface moisture flux at a latitude of $41.5^{\circ} \mathrm{N}$ indicate that there were no large differences in the fluxes between the CNTL and PGW simulations by 2100 UTC 16 August 2016 (Figs. $4 \mathrm{a}$ and $4 \mathrm{~b}$ ). In the warming climate, the southerly winds were weaker than those in the CNTL simulation, because the PGW typhoon was still about $700 \mathrm{~km}$ away from the region (Figs. 3e and $3 \mathrm{~g})$. However, air masses with water vapor $>20 \mathrm{~g} \mathrm{~kg}^{-1}$ appeared at $148^{\circ} \mathrm{E}$ around 0300 UTC 16 and extremely large amounts of water vapor $>22 \mathrm{~g} \mathrm{~kg}^{-1}$ reached eastern Hokkaido by 1800 UTC 16. Meanwhile, amounts of water vapor were relatively small $(<$ $18 \mathrm{~g} \mathrm{~kg}^{-1}$ ) in the CNTL simulation. Large differences between the CNTL and PGW simulations during the PREs (Event-I) appeared in the convective instability; eastern Hokkaido in the PGW simulation possessed considerably large convective available potential energy (CAPE) above $1200 \mathrm{~J} \mathrm{~kg}^{-1}$ (Fig. 4d). Because changes in air temperature was large in the upper troposphere in the warming climate (See Fig. $2 \mathrm{f}$ in Kanada et al. 2017), the large CAPE was attributed to the increases in near-surface moisture. Indeed, the both lifting condensation level and level of free convection decreased largely in the regions with extremely large amounts of water vapor $>22 \mathrm{~g} \mathrm{~kg}^{-1}$ in the PGW simulation (not shown). In contrast, CAPE in the CNTL simulation was relatively small during Event-I (Fig. 4c). The results indicate that eastern Hokkaido in the PGW simulation was dominated by the increased moisture and stronger convective instability that allowed intense convection for PREs. Meanwhile, CAPE during Event-II was small in the both CNTL and PGW simulations, because convective instability of the typhoon core region was neutralized by the intense secondary circulation (Kanada and Wada 2015).

The statistical characteristics of convection for PREs (Event-I) and typhoon passage (Event-II) were investigated by using the cumulative frequency distribution of vertical velocity (e.g., Rogers et al. 2013) (Fig. 5). It should be noted that the convection over eastern Hokkaido was most intense for PREs in the warming climate. In general, the convective activity over eastern Hokkaido was more intense for PREs (Event-I) than during the passage
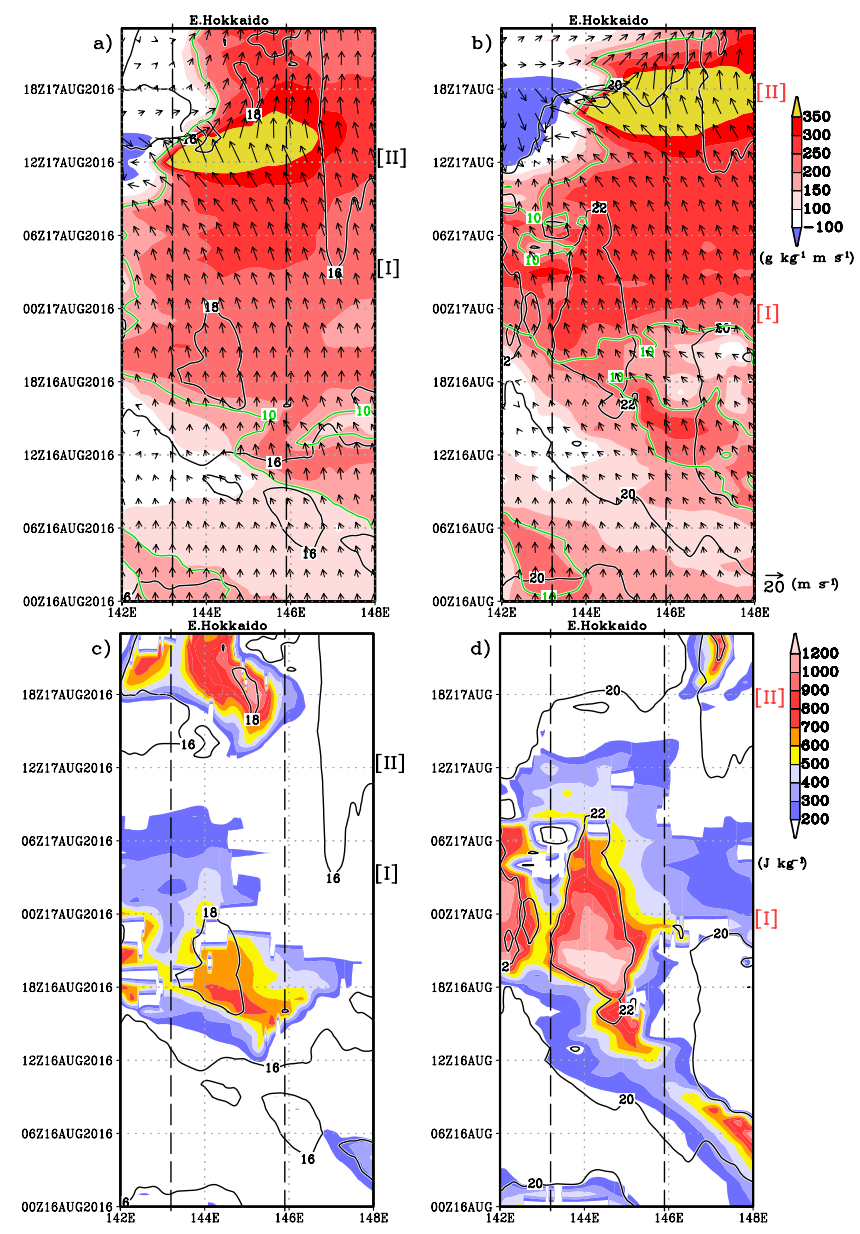

Fig. 4. Longitude-time cross sections of moisture flux (color) and horizontal wind (arrows) at an altitude of $10 \mathrm{~m}$ at a latitude of $41.5^{\circ} \mathrm{N}$ in the (a) CNTL and (b) PGW simulations. Green and black contours indicate southerly winds of $10 \mathrm{~m} \mathrm{~s}^{-1}$ and water vapor mixing ratios of 16 and 18 (CNTL), and 20 and 22 (PGW) $\mathrm{g} \mathrm{kg}^{-1}$. Vertical dashed lines indicate eastern Hokkaido. Time progresses upward. (c)-(d) Same as (a)-(b) but for CAPE.

of the typhoon core region (Event-II). Figure 4 and profiles of equivalent potential temperature (EPT, Figs. $5 \mathrm{c}$ and $5 \mathrm{f}$ ) indicate extremely high near-surface EPT around $370 \mathrm{~K}$ during Event-I with large convective instability, although the EPT in the upper troposphere also increased in the warming climate. With the CAPE $>1200 \mathrm{~J} \mathrm{~kg}^{-1}$, tall and intense updrafts developed (Fig. 5a) in eastern Hokkaido and produced large amounts of graupel in thick layers between the altitudes of 5 and $12 \mathrm{~km}$ (Fig. 5b) in the warming climate. These features resulted in intense rainfall in limited areas. On the other hand, the updrafts in the CNTL simulation with small CAPE $\left(<600 \mathrm{~J} \mathrm{~kg}^{-1}\right)$ were relatively weak and produced smaller amounts of graupel compared with those in the PGW simulation. In contrast, the near-surface EPT decreased and the convective instability was almost neutralized during the passage of the typhoon core region in both climates. The most intense updrafts associated with the typhoon passage (Event-II) were tall but weaker than those for PREs even in the PGW simulations (Fig. 5d). However, increased moisture in the warming climate contributed to the production of considerable amounts of snow that enhanced rainfall associated with the typhoon passage over a widespread area in eastern Hokkaido (Figs. 3 and 5).

\section{Summary and discussion}

To understand the impact of global warming on typhoon- 

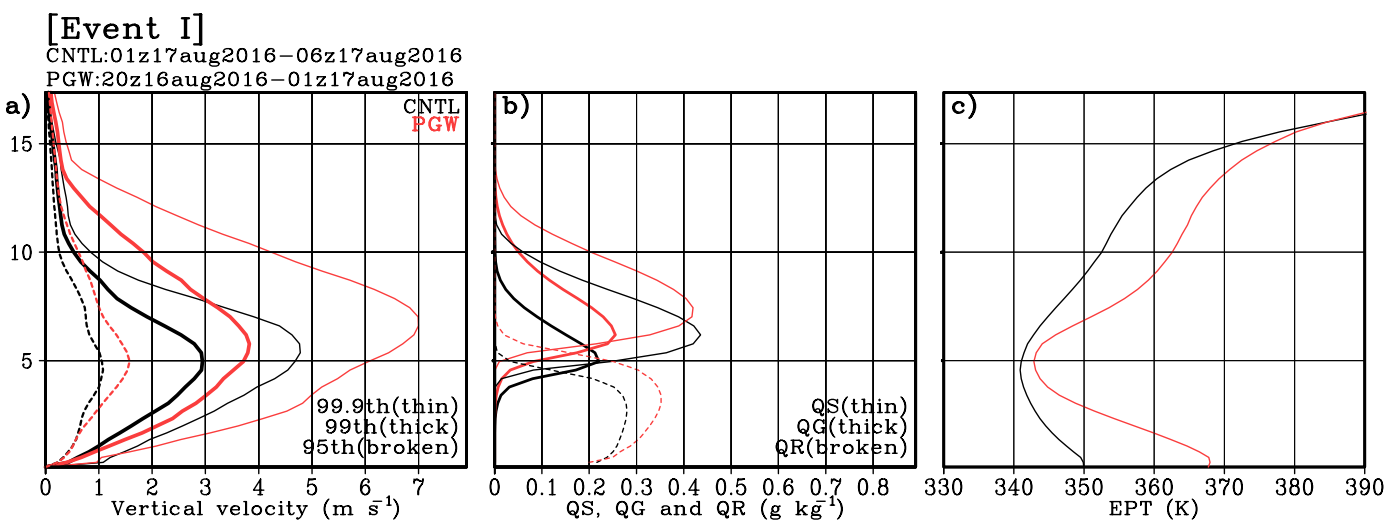

[Event II]

CNTL: 11 z17aug2016-16z17aug2016
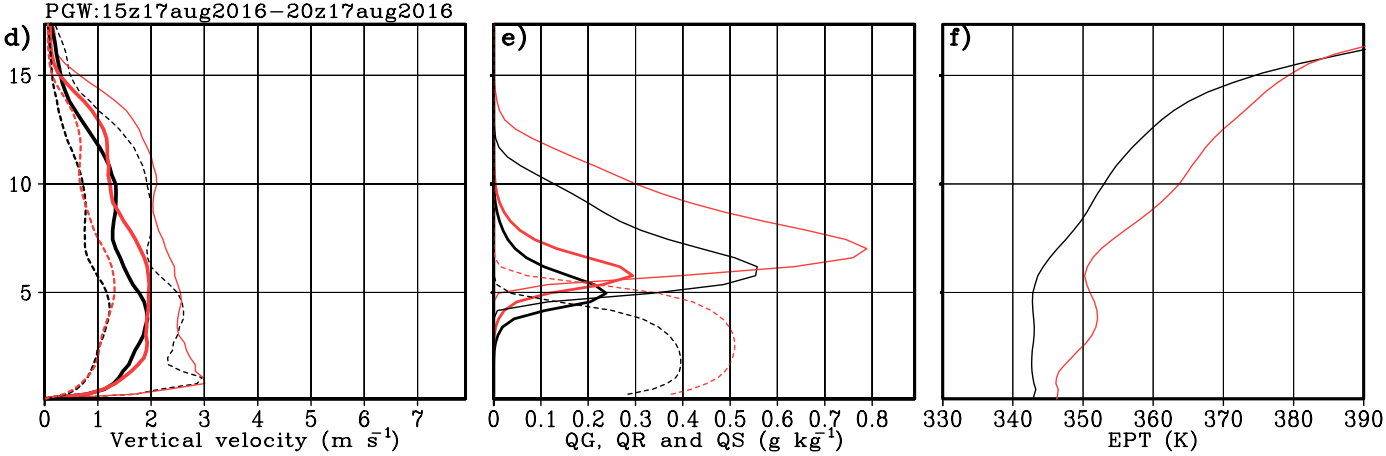

Fig. 5. Vertical profiles of (a) the cumulative distribution of vertical velocity, (b) snow (QS, thin lines), graupel (QG, thick lines) and rainwater (QR, broken lines) mixing ratios, and (c) equivalent potential temperature (EPT) in eastern Hokkaido during Event-I for the CNTL (Black, 0100 UTC-0600 UTC 17) and PGW (red) (2000 UTC 16 and 0100 UTC 17) simulations. Dashed, thick, and thin lines in (a) represent the $95^{\text {th }}$, $99^{\text {th }}$, and $99.9^{\text {th }}$ percentiles of velocity, respectively. (d)-(f) Same as (a)-(c) but for Event-II for the CNTL (1100 UTC-1600 UTC 17), and PGW (1500 UTC 17) simulations.

related rainfall in the midlatitude regions, numerical experiments on Typhoon Chanthu (2016), which caused heavy rainfall in eastern Hokkaido, were conducted by using a three-dimensional atmosphere-ocean coupled regional model with a horizontal resolution of $0.04^{\circ}$ in current and pseudo-global warming (PGW) climates. Typhoon-related rainfall in eastern Hokkaido is projected to increase under global warming (Fig. 2). In the warming climate, the typhoon traveled northward at relatively slow translation speeds and the landfall time was delayed for $6 \mathrm{~h}$ compared to the CNTL typhoon. The weakening of the jet streak due to the reduction of baroclinicity was a possible factor for the slower translation speeds (Figs. 1a). In addition, the southeasterly winds associated with the typhoon transported extremely warm and moist air masses from the southern sea, increased the convective instability and intensified the predecessor rainfall events with intense convection $24 \mathrm{~h}$ before landfall (Fig. 3) and led to a longer rainfall period in the warming climate (Fig. 3a). Under conditions of the increased convective instability, deep and intense updrafts developed over future eastern Hokkaido and caused intense rainfalls during the period. Meanwhile, convection in the current climate with smaller convective instability was relatively weak and the predecessor rainfall events was not significant (Figs. 4 and 5). Convective instability around the typhoon core-region was also small, however, increased water vapor helped to enhance rainfall of typhoon to cause moderate rainfall over a widespread area.

The present study indicates that large increases in water vapor in the lower troposphere can overcome the stabilization of atmospheric conditions and cause more intense and larger amount of rainfall in a warming climate. It should be noted that to clarify changes in the frequency of typhoons that hit eastern Hokkaido, further studies using the results of climate runs by global circulation models are required. Nonetheless, the high-resolution coupled model shows that tall and intense updrafts can develop in the midlatitude regions even when a typhoon is about $700 \mathrm{~km}$ away from the region. In the current climate, $16 \mathrm{~g} \mathrm{~kg}^{-1}$ of near-surface water vapor (Fig. 4) caused nearly $200 \mathrm{~mm}$ of $48 \mathrm{~h}$ rainfall amounts in eastern Hokkaido. If $20 \mathrm{~g} \mathrm{~kg}^{-1}$ of water vapor, which is comparable to the amount during torrential heavy rainfall over southern Japan in the current climate (e.g., Kato 1998), will be supplied, torrential heavy rainfall similar to what occurs in southern Japan could be expected in midlatitude regions such as Hokkaido.

\section{Acknowledgements}

The authors are grateful to two reviewers and an editor for instructive comments. This study was supported by the Ministry of Education, Culture, Sports, Science and Technology of Japan under the framework of the TOUGOU Program. Numerical simulations were performed using the supercomputing system at Nagoya University.

Edited by: K. Yasunaga

\section{Supplement}

Supplement 1 describes detailed information for the models and methodology.

\section{References}

Aiki, H., K. Takahashi, and T. Yamagata, 2006: The Red Sea outflow regulated by the Indian Monsoon. Cont. Shelf Res., 26, $1448-1468$.

Aiki, H., J. P. Matthews, and K. G. Lamb, 2011: Modeling and energetics of tidally generated wave trains in the Lombok 
Strait: Impact of the Indonesian Throughflow. J. Geophys. Res., 116, C03023, doi:10.1029/2010JC006589.

Aiki, H., M. Yoshioka, M. Kato, A. Morimoto, T. Shinoda, and K. Tsuboki, 2015: A coupled atmosphere-ocean-surface-wave modeling system for understanding air-sea interactions under tropical cyclone conditions. Bull. Coastal Oceanogr., 52, 139-148.

Bosart, L. F., J. M. Cordeira, T. J. Galarneau Jr., B. J. Moore, and H. M. Archambault, 2012: An analysis of multiple predecessor rain events ahead of Tropical Cyclones Ike and Lowell: 10-15 September 2008. Mon. Wea. Rev., 140, 1081-1107, doi:10.1175/MWR-D-11-00163.1.

Collins, M., and co-authors, 2013: Long-term climate change: Projections, commitments and irreversibility. Climate Change 2013: The Physical Science Basis. Contribution of Working Group I to the Fifth Assessment Report of the Intergovernmental Panel on Climate Change, Stocker, T. F., D. Qin, G.-K. Plattner, M. Tignor, S. K. Allen, J. Boschung, A. Nauels, Y. Xia, V. Bex and P. M. Midgley, Eds., Cambridge University Press, Cambridge, United Kingdom and New York, NY, USA.

Emanuel, K. A., 1986: An air-sea interaction theory for tropical cyclones. Part I: Steady-state maintenance. J. Atmos. Sci., 43, 585-605.

Fujibe, F., 2015: Relationship between interannual variations of extreme hourly precipitation and air/sea-surface temperature in Japan. SOLA, 11, 5-9.

Fujita, M., and T. Sato, 2017: Observed behaviours of precipitable water vapour and precipitation intensity in response to upper air profiles estimated from surface air temperature. Scientific Reports, 7, doi:10.1038/s41598-017-04443-9.

Galarneau, T. J., Jr., L. F. Bosart, and R. S. Schumacher, 2010: Predecessor rain events ahead of tropical cyclones. Mon. Wea. Rev., 138, 3272-3297, doi:10.1175/2010MWR3243.1.

Hill, K. A., and G. M. Lackmann, 2011: The impact of future climate change on TC intensity and structure: A downscaling approach. J. Climate, 24, 4644-4661, doi:10.1175/2011 JCLI3761.1.

Ito, R., T. Takemi, and O. Arakawa, 2016: A possible reduction in the severity of typhoon wind in the northern part of Japan under global warming: A case study. SOLA, 12, 100-105, doi:10.2151/sola.2016-023.

Kanada, S., and A. Wada, 2015: Numerical study on the extremely rapid intensification of an intense tropical cyclone, Typhoon
Ida (1958). J. Atmos. Sci., 72, 4194-4217, doi:10.1175/JASD-14-0247.1.

Kanada, S., T. Takemi, M. Kato, S. Yamasaki, H. Fudeyasu, K. Tsuboki, O. Arakawa, and I. Takayabu, 2017: A multi-model intercomparison of an intense typhoon in future, warmer climates by four 5-km-mesh models. J. Climate, 30, 60176036, doi:10.1175/JCLI-D-16-0715.1.

Kato, T., 1998: Numerical simulation of the band-shaped torrential rain observed over southern Kyushu, Japan on 1 August 1993. J. Meteor. Soc. Japan, 76, 97-128.

Kobayashi, S., and co-authors, 2015: The JRA-55 reanalysis: General specifications and basic characteristics. J. Meteor. Soc. Japan, 93, 5-48, doi:10.2151/jmsj.2015-001.

Miyazawa, Y., R. Zhang, X. Guo, H. Tamura, D. Ambe, J.-S. Lee, A. Okuno, H. Yoshinari, T. Setou, and K. Komatsu, 2009: Water mass variability in the western North Pacific detected in a 15 -year eddy resolving ocean reanalysis. J. Oceanogr., 65, 737-756, doi:10.1007/s10872-009-0063-3.

Mizuta, R., H. Yoshimura, H. Murakami, M. Matsueda, H. Endo, T. Ose, K. Kamiguchi, M. Hosaka, M. Sugi, S. Yukimoto, S. Kusunoki, and A. Kitoh, 2012: Climate simulations using MRI-AGCM3.2 with $20-\mathrm{km}$ grid. J. Meteor. Soc. Japan, 90A, 233-258, doi:10.2151/jmsj.2012-A12.

Mizuta, R., O. Arakawa, T. Ose, S. Kusunoki, H. Endo, and A. Kitoh, 2014: Classification of CMIP5 future climate responses by the tropical sea surface temperature changes. SOLA, 10, 167-171, doi:10.2151/sola.2014-035.

Mizuta, R., and co-authors, 2017: Over 5000 years of ensemble future climate simulations by $60 \mathrm{~km}$ global and $20 \mathrm{~km}$ regional atmospheric models. Bull. Amer. Meteor. Soc., 13831398, doi:10.1175/BAMS-D-16-0099.1.

Rogers, R. F., P. Reasor, and S. Lorsolo, 2013: Airborne Doppler observations of the inner-core structural differences between intensifying and steady-state tropical cyclones. Mon. Wea. Rev., 141, 2970-2991.

Trenberth, K., 2011: Changes in precipitation with climate change. Climate Res., 47, 123-138.

Tsuboki, K., and A. Sakakibara, 2002: Large-scale parallel computing of Cloud Resolving Storm Simulator. High Performance Computing, H. P. Zima et al., Eds., 243-259, Springer, New York.

Manuscript received 13 September 2017, accepted 13 November 2017 SOLA: https://www.jstage.jst.go.jp/browse/solal 